nourishment or stimulants, you will have to seek medicinal means of subduing it, as such excitement soon ends in irremediable exhaustion. Opium, however, must not be included amongst these means. Its action is always ambiguous in old age, and in senile dementia those degenerative changes in the vessels, which are so frequently present, contraindicate its use. Even where the vessels are sound it may be hurtful, by strengthening the tendency to that vague drowsiness which is apt to lapse into coma, with effusion of serum, or by disordering the functions of the prima viæ. I should say that it is almost always contraindicated in senile dementia. A less dangerous sedative is found in hyoscyamus, which will generally secure repose in such cases, without doing damage in any other direction. I can attest its value, from long experience of it in senile dementia. Beginning with a drachm dose of the tincture, or succus, we increase the amount, until its soothing influence is manifested, and rarely require to exceed half an ounce as a dose. If hyoscyamus fail, cannabis Indica may be tried, with great caution. Chloral, as you know, I do not employ in such cases. When the excitement coexists, with a copious excretion of lithates from the kidneys, it may sometimes be mitigated by the administration of alkalies.

If muscular trembling be excessive, conium in large doses (from two to four drachms) of the succus will probably prove a palliative. Carbonate of iron or spirit of turpentine often also affords some relief.

\section{ADDRESS ON THE PROGRESS OF MEDICINE.*}

\section{BY JOHN RICHARD WARDELL, M.D., F.R.C.P., Physician to the Tunbridge Wells Infirmary.}

[Concluded from page 605 of last number.]

No class of diseases is more familiarly, more thoroughly, known, than diseases of the chest. The great work of Laennec inaugurated a new era in thoracic pathology. It conferred a positiveness in diagnosis which can scarcely in such full measure be said to obtain in judging of any other order of ailments. Nor can it be held, though multitudes of observers have availed themselves of Laennec's discovery, that much of real practical significance has been done beyond what he accomplished. Prior to the recognition of the physical signs, capillary bronchitis and pulmonary collapse could not be distinguished from pneumonia; cardiac diseases were vaguely referred to ossification; effusions could only be decided upon by the Hippocratic symptom of succussion; and aneurisms could alone be guessed at by the more general and objective symptoms. The extent and degree of pneumonia can now be decided upon with not a little of certainty; and its treatment is more successful from a more rational pathology. Those intercurrent forms which constitute episodes in the graver epic of a wider lying general or constitutional malady, and with which frequently the pleura becomes locally implicated, can now be detected with much niceness and precision. Accumulated facts have made knowledge which has ceased to be contested. Pericarditis and endocarditis, we believe, never occur but in rheumatism ; fibrin on the margins of the valves is looked upon as a deposit, and not an inflammatory exudate, on the valves themselves; hypertrophy now means cerebral or other hæmorrhages, rather than direct injurious influence on the action of the heart itself; extensive binding down of the lung to the costal wall, it is now allowed, may be compatible with lengthened life, and almost with health; and morbic anatomists now admit that considerable pericardial adhesion may eventuate with comparative recovery. The stethoscope has placed the modern physician on a vantage-ground which could in no wise have been hoped for by the older practitioners. They had not the means of arriving at any correctness in judging of the morbid changes within the thoracic walls. Thirty years ago, the average duration of phthisis was about two years. Under improved treatment, it is now estimated at four years. It has also been conceded that, in some cases, the disease admits of positive cure. Though such instances are exceptional, still they are sufficient to inspire us with the hope that with the progressive increase of our knowledge will come greater and greater success in this direction of our encleavours. Post mortem researches teach us that pulmonary cavities, even of considerable dimensions, may contract and heal up, and absolute recovery be the result; indeed, it may be added that such obliteration of these excavations are more usual than in former years was supposed. Our definition of the pathology of phthisis is more exact and defined. We now talk of fibrosis of the lung, a degenerative deposit which bears much resemblance to the amyloid substance; of embolic phthisis, in which are cheesy deposits and disintegrated bloodclots; of bronchial and pneumonic phthisis, characterised by cheesy matter and ulceration of the bronchi, or with exudation into the pulmonary tissue;

* Read before the East Sussex and West Kent District Branches. and of syphilitic phthisis, with gummata allied with the cheesy product. These pathologic distinctions in the description of phthisis render its treatment more successful. The late animated and diffuse debates on tuberculosis have, with other elucidations of its nature, clearly shown the infectious properties of phthisical inflammation. It is now believed by Niemeyer and others that phthisis may follow hæmoptysis without genetic connection between the hacmorrhage and the pneumonic process; and that blood retained in the alveoli gives rise to inflammatory products, which undergo the cheesy change, and that such metamorphosis is followed by tubercle. Grey and yellow tubercles are now shown as being identical; and an intermittent pyrexia or chronic phthisis has latterly been looked upon to denote the absorption of caseous matter. Such are some of our advances relative to this common and justly dreaded disease. The alternation with, or vicarious occurrence of, bronchitis in gout, is an important practical advance; and in bronchitic asthma we are more clearly impressed with the implication of the ganglia and the influence of the vaso-motor function. Pleurisy of the idiopathic or primary character is now considered to be far more rare than was formerly supposed ; indeed, if we exclude mechanical and physiological causes, primary pleurisy is exceedingly rare. The types of this disease which we so commonly see are rather the complications or sequential conditions of some foregoing visceral affection, or some constitutional malady which has already produced an impress upon the organism. We contemplate its presence very much in the same way as we contemplate the presence of pneumonia, and we try to discover the indications of some antecedent vice in the system. We more greatly suspect its insidious character; we are aware of its not infrequent association with pyæmic infection, with pulmonary phthisis, with the various forms of renal disease; and in all cases of pneumonia there is, perhaps, a greater or less degree of pleuritic inflammation of the fibrinogenic type. The competent manner in.which we can now diagnose fluid in the cavity of the chest, and elect between trusting to absorption and having recourse to thoracentesis, ranks amongst the greatest improvements in modern medicine. This operation is shown to be followed with as little danger as blood-letting. By its timely adoption, as compared with the non-instrumental interference, and the vacillating practice of the past, a large number of lives are now saved. The morbid anatomy of pleuritis with effusion, as well as clinical history, have established the axiomatic rule, that paracentesis thoracis should be had recourse to early, and before the pyogenic membranes become organised, and the lung-substance is bound down and compressed beyond the powers of expansion. The discovery of albuminous expectoration following thoracentesis, made by M. Pinault, and which last year was importantly brought forward at the Academy of Medicine in Paris, as illustrated by the cases narrated by MM. d'Espine, Woillez, Marrotte, Behier, and Terrillon, is a curious addition to pathological acquirements.

Though diagnosis is less certain in lesions of the abdomen than in the chest, still the knowledge of abdominal diseases has been most progressive. The viscera in this cavity being from numerous causes subject to great variation in size, configuration, and position, much difficulty will always be experienced in correctly comprehending the particular maladies which are there to be found. It is now affirmed that no parts in the body have such immunity from disease as the jejunum and the valvulæ conniventes. We have more trustworthy guides for observation on deciding between simple and malignant disease of the stomach. We maintain that acute idiopathic gastritis does not occur in this as it is said to occur in tropical countries. The discovery of sarcinæe ventriculi led to the cure of a tiresome stomach complaint. We know that the sulphites of potash and soda destroy these fungi, as certainly as the sulphites and sulphurous acids destroy these vegetable parasites in the skin. Between torpor of the colon and melancholic depression there is intimate relation. Ulceration of the ileum is never seen in any acute disease except in enteric fever. Ulcerations in the lower third occur in chronic phthisis, but they differ not only in their pathologic characteristics, but in their relation to the axis of the bowel. Cancer we know to be far less frequent in the ileum than in the colon ; and if the pylorus be excepted, it is more prone to be located at the sigmoid flexure than at any other part of the digestive tube. Perforation of the intestinal serous covering is most rare, except in enteric fever. Respecting our recent knowledge of the liver, many facts have been accumulated. It has been ascertained that the hepatic cells perform the function of secreting from the blood a substance named glycogen, which is rapidly transformed into glucose or animal starch; and that this principle is carried into the heart, thence to be oxidised in the respiratory process and evolve animal heat. This glycogenic function is a physiological fact, of much significance in a practical point of view. In acute or yellow atrophy, it has been discovered that the urine exhibits remarkable changes, as there may be the total disappearance of urea, uric acid, the chlorides, sulphates and phosphates; and these are replaced by the fibro-albuminous pro- 
ducts named leucine and tyrosin. The waxy or amyloid deposit recognised in this organ is considered to be consequent on ulceration of the osseous tissue and long-standing syphilis. Palpation, percussion, and feeling the notches in the free edge, tell us much of splenic enlargement. The latest additions to our information relative to the spleen are chiefly physiological. In the intertrabecular spaces are doubtless first formed the molecules which become developed into blood-corpuscles; and it is believed that in the pulp they also become disintegrated. Such vital processes being there elaborated, it can thus be understood how anæmia and disease of the spleen stand in intimate correlation. In leucocythæmia, that affection which is characterised by excess of colourless corpusclesand diminution of blood-corpuscles, great light has been thrown upon the splenic lesion by which it is accompanied. Excess of fibrine and decrease of coloured corpuscles are the two primary cardinal changes in leucocythrmia. Such are some of the new facts respecting diseases within the abdomen.

In glancing at the nervous system, much in recent years has been done; still, it is undeniable that a great deal of ambiguity remains in diagnosticating cerebral affections, because the degree of objective symptoms is frequently by no means the exponent of the degree of morbid action. We are often and correctly guided by physiological phenomena; but sometimes there may be lesion and extension when least suspected. A patient some time ago was under my care, and there was found in one of his hemispheres a tumour of the size of a China orange. I recollect another man who had a small osseous formation at the base not larger than a pea, which had produced terrible epileptiform attacks. Both had convulsions, both cases ended fatally, but the respective amounts of lesion very widely differed. It was the location of these growths which accounted for the sum of their effects, and which no diagnostic acumen during life could explain. Schiff has shown that augmented heat produced by activity of the nerve-centres is primarily due to the vaso-motor nerves; and the experiments of Heidenhain, Riegel, and Fick, have solved some interesting problems relative to the extrication of animal heat. In blood-poisoning, we are more impressed with the peripheral irritation which produces phenomena in the great centres. The vaso-motor function renders explicable much which before was ill understood; epilepsy in age we now refer to retrograde metamorphosis of the tissues; and it is generally accepted that this disease, epilepsy, which has an etiology so multiform, is always primarily caused by anæmia ; and when there is muscular atrophy in the young, we refer the wasting to a foregoing brain-change. Again, softening of the cord, we now know, always means more or less of anæsthesia as the accompaniment; and it has lately been discovered that induration of the cord is followed by regular and rhythmic paralytic action of the voluntary muscles. It is a great and an important advance that locomotor ataxy, as Todd and Duchenne were the first to show, ought not to be confounded with paraplegia. Its chief characteristics may be defined as the want of co-ordinating motor power in the lower extremities. We also now are aware that the structural disease is confined to the posterior columns of the cord, and very generally to its dorsal portion. Some pathologists believe, and I think clinical observation con firms the opinion, that the excess of cerebro-spinal fluid gravitating into the theca vertebralis, and at a given point producing pressure, may act as a cause. In several cases which have been under my care in the infirmary, I have found that long continuance in the horizontal posture has greatly aided remedies. The microscope shows the diseased part to have undergone the fatty change. One of the analogues of locomotor ataxy, and occurring in the brain, is that morbid condition now known as aphasia, or the loss of articulate language. And it is, as I need hardly remind my hearers, a very curious fact, that its pathological cause is now defined to be blockage of the middle cerebral artery of the left side by an embolon from valvular disease. It may, however, be produced by other causes, as hæmorrhage, tumours, and gummata ; indeed, I think it is more frequently the result of specific gumma than is generally allowed. Not long ago, a young man came into the infirmary under my care. He was hemiplegic and inarticulate. He had aphasia, agraphia, and was amnesiac. There were proofs of secondary syphilis. He had fifteen-grain doses of the iodide of potassium, and, as he improved, was ordered electro-galvanism. In the course of a few weeks, he had made a full recovery. Had time allowed, a good deal that is new might have been given relative to the effects of the syphilitic poison on the nervous system, the knowledge of which constitutes one of the many recent and marked advances in our art.

I cannot here do more than incidentally refer to that contested question, the change of type of disease, which at one time received such general acceptance, but which doctrine, in my own humble opinion, never seemed so tenable as many maintained, because the phenomena of disease, like the phenomena of other natural processes, are doubtless based upon fixed and immutable laws; because we have proofs that some acute affections now run their course as they ran it generations ago ; and because this change of type, so called, was too sudden, abrupt, and unexampled in its accession to be reconcilable with the theory of some occult and extrinsic alteration, as being a sufficient causation for those modified views and that reversal of treatment which so rapidly followed the declaration of this dogma. It is clear that epidemics vary in the degree of their intensity, doubtless from differences of physical conditions, if we could but demonstrate them, which enter into their etiological state, which may be either telluric or atmospheric, or both ; still, their broad outlines, their characteristic features, remain the same. This new notion became the facile hypothesis which, with little trouble, commended itself for adoption, and which supplied a ready answer as to any questioning of novel views. But it never seemed so philosophic as to warrant the extreme lengths to which the theory put into practice was pursued. Whoever will compare the descriptions by Fracastorius and Cardanus of typhus of the sixteenth century, will at once see how in all essentials they apply to the graver forms of typhus of our own times. The accounts which we have of fever in the seventeenth century by Riverius, Mangetus, Willis, and others, are the accounts of the enteric form which we all now know so well. Rutty was the historian, under another name, of relapsing fever a hundred years before its characteristics and its distinctiveness were more fully described in 1843 and $\mathrm{I} 844$. The records of scarlet fever by Sydenham, and Fothergill's sore-throat, are applicable to diseases which we all see daily in our practice ; and the course of variola vaccinia is precisely the course which it ran eighty years ago.

Had time allowed, other arguments might have been given to show the invalidity of the uncompromising manner in which change of type theorists insisted upon their creed. It may, however, in passing, be observed that this notion quickly succeeded Bright's discovery, which was about to sweep away many pathological dogmas and theoretical phantasies. The Vienna school had about this time promulgated the doctrine of crasis. Microscopical anatomists and analytic chemists had begun to point out molecular degeneration and secretional abnormities, the ocular proofs of an impaired vitalism. Such terms as metastasis, idiopathic, dynamic, and sthenic, began to lose their hold on the medical mind ; and symptoms heretofore regarded as the expressions of excess of strength were, in more philosophic reasoning, to be looked upon as the evanescent excitations incident to degeneration and debility. Febrile affections, pneumonia, and other acute diseases were gradually treated with more success, because the treatment was in clearer manner founded on sounder pathology. The blood-letting in fever, which had erroneously been advocated by Welch, Clutterbuck, and Armstrong, from this new knowledge and closer clinical observation, became discarded, and consequently the mortality became diminished.

In the cursory sketch which I can only now venture to give of many other additions to our information, reference may be made to our knowledge of cerebro-spinal meningitis, diphtheria, hereditary syphilis, and the great class of microphytic diseases; to the wonderful facts brought to light relative to entozoic affections ; to the far better understanding of the complaints of infancy and childhood-the term infantile remittent being really another name for ignorance rather than the expression of correct diagnosis; to the more accurate distinction which we draw between gout and rheumatism; to the fact that lactic acid conveyed into the blood artificially will produce symptoms resembling rheumatism and veritable endocarditis ; to our greater acquaintance with those congenic conditions, tuberculosis and strumosis; to the fact that cancer, like tubercle, is a debased organic product: and it would be easy to continue this enumeration.

The majority of those whom I now have the honour of addressing will well remember, on the commencement of the practice of their profession, what confused notions prevailed respecting, and how much of ambiguity overshadowed, the great questions involved in the study of continued fever. They will be able to call to mind how authorities differed, and how much of doubt and uncertainty varying and prominent symptoms engendered in the mind of the physician. The definitions of the three types of continued fever, which we can now give, and which are of such inestimable worth in a practical point of view, were then unknown. With these descriptive accounts of their essential differences, the mists which once obscured the pathology of fever have passed away, and trustworthy landmarks stand out-founded on the bases of truth and factas guides to all future times. I shall not stop to indicate in any detail the cardinal characteristics of each species which are now so familiarly known, but content myself with the mention of a few of the more important considerations. It is curious, but the Hippocratic and Galenic theories have received confirmation in our own day by the researches of Virchow and Traube. It is now acknowledged that, whatever may be the changes which fever-poison primarily exerts on the blood, the first intelligible physiological effects are in the nervous system, and in the sym. 
pathetic and vagus in especial. The increased oxidation of nitrogenous tissues, the commensurate evolution of heat, augmented heart's action, and the non-elimination of metamorphosed products, are the great predominating and fundamental changes in fever. These are the forerunners of all other morbid processes, and between the sum of their excess and the degree of perverted secretion there is correspondent relation. Increase of heat is the symptom pathognomonic of pyrexia. In the recognition of specific differences in fever, we are by parity of reasoning compelled to admit that their material causes differ. The character of tissue-change is determined by the character of the specific poison. It is the opinion of modern pathologists, that the materies morbi always invades the organism from without. We now have a vast array of proofs that overcrowcling, bad or insufficient food, and mental depression, are the main circumstances which precede epidemics of typhus; that decomposed organic matters produce the enteric form; and that relapsing fever is so apt to follow on the heels of destitution, as to have acquired the synonym of famine-fever. Such are the cognisable, the preventable states, entering into their causation. Those vital and chemical processes which produce combustion of what is called the store-albumen of the blood, mainly give off urea and uric acid; and it is to the retention of these urinary solids that prominent symptoms and intercurrent affections are almost if not wholly owing. It is from these products of metamorphosis that congestion, a low form of inflammation, and uræmia, supervene. Hence, in treatment, to favour elimination is of supreme importance. Before all this new light shone forth, our remedies were prescribed with great dubiousness and much perplexity. We could not anticipate events. We did not know what to expect during the course of the respective species. By the nonrecognition of those types which are so distinct and reverse in their essence and phenomena, fears were then unnecessarily aroused, and dangerous symptoms were sometimes regarded with too little heed. In this our day, we know typhus by its mode of accession, its rubeoloid rash, the absence of diarrhœa, the grave impress made on the great nervous centres, the drawing in of the abdomen, and the average date of the crises. In enteric fever, its slower beginning, the lenticular rosecoloured spots, diarrhœa, tympany, pain and gurgling in the right iliac fossa, the cleaner tongue, and less cerebral disturbance, tell plainly of its nature. The sudden accession, quick pulse, great heat, icteric tendency, the abrupt resolution by diaphoresis when the apyrexial state becomes at once complete, and, in the course of a few days, the repetition of primary symptoms, pronounce the relapsing type. Nearly thirty years ago, I pointed out the fact that the temperature in relapsing fever may be IO7 or IOS deg. Fahr. without the case assuming an alarming form. In typhus, and in the enteric species, we contemplate with deep and just anxiety such a high reading of the thermometer. Again, in the two last named types, sudden and powerful diaphoresis is not unfrequently a fatal symptom. In each of these three species, we now not only know great cardinal and distinguishing characteristics during life, but what to look for-all changes which we do not expect to discover till after death. In typhus, there is no specific lesion. We do, however, in typhus find brain-atrophy, œdema of the pia mater, and active and passive congestion; but in enteric fever we find specific lesions in the ulceration of the agminate and solitary glands of the ileum, and sometimes sparsely scattered in the colon. In a number of post mortem examinations made on those who had died of relapsing fever, I did not in a single instance find these ulcerations, but always more or less of splenic disease. In typhus, we dread cerebral mischief and muscular degeneration enfeebling the heart; in enteric fever, failure of cardiac power from ganglial impression made by the specific poison, intestinal hremorrhage, and perforation; and in relapsing fever, cholæemic and uræmic poisoning are often associated with the fatal catastrophe. Some time ago, at one of our Branch meetings, I read some cases of uræmic poisoning, and showed how the phenomena of this mode of blood-contamination closely resemble the phenomena of essential typhus. The typhoid state of the specific pyrexia, and the typhoid state from renal disease, are sometimes so correspondent, that the thermometer alone can solve the difficulty. I know no instance in which thermometry so opportunely and in such elucidative manner comes to our aid. Again, during the first week of continued fever, to note the temperature is often to conduct us to a right diagnosis. Such are some of our gains concerning continued fevers.

Gentlemen, I will no longer encroach on our limited time; and I may say, with the poet,

$$
\text { "Ante diem clauso componat vesper Olympo." }
$$

I have endeavoured to concisely indicate some of those great advances which have latterly been accomplished, and which have signally extended the boundaries of medical science; but a vast array of acquisitions of the deepest interest remain untold. Had the opportunity been given, much in physiology and therapeutics might have been recounted; and, as pertains to preventive medicine, the onward march has been commensurate with any of those kindred subjects which come within our studies. Whatever progress may have been made in any of the physical sciences, the progress in medicine has been equal to that of any. During the last five-and-twenty years, more has been achieved than in any previous century. A higher standard of education, better clinical teaching, and more thoroughness of acquirement, are telling favourably on the student. Silent workers-and they are many-in the wards, the laboratory, and the study, are evolving great truths, and continually fortifying the busy practitioner with fresh facts of inestimalile value. The medical profession is being held in higher and higher estimation. There never was an age in which more zeal, more ability, and more loyalty, were found in its ranks; and there never was an age in which our exalted vocation was pursued with such success as it is in the present day. An enormous accumulation of facts-irrefragable, applicable, priceless facts-have made great stores of new knowledge, which daily is wisely, humanely being brought to bear in enabling us more certainly, more successfully to wage our war against the ravages of disease and death; and this knowledge, which is broadly recognised, solid, immutable, "will remain as the Danube and the Alps remain, because it is founded on the Beautiful and the True".

\section{THE LIVER I N JAU N D ICE.}

By J. WICKHAM LEGG, M.D.,

Casualty Physician and Demonstrator of Morbid Anatomy to St. Bartholomew's Hospital.

\section{[Concluded from $p .608$ of last number.]}

THE changes which the parenchyma of the liver suffers in obstruction to the bile-ducts have been very little studied. Oskar Wyss (Airhiz für pathol. Anat., I S66, vol. xxxv, p. 553), Leyden (Beiträgse aur Pathologie des Icterus, Berlin, I866, p. 85), and Heinrich Mayer ( $T_{t}$ dizin. Fahrbiücher heraussegeben von der k.k. Gesellschaft der A 'rite':u Wien, 1872, Heft II, p. 133), are almost the only three observers who have paid any detailed attention to this state. The liver at first increases in size; it becomes of a deep bilious or olive-green colour, and is said to be itself jaundiced. Its consistence is increased, and the surface and section are somewhat granular. If the jaundice continue long, the liver wastes.

The changes in the cells and in the connective tissue of the liver may be considered apart. In all cases of long continued obstruction to the bile-ducts, the connective tissue grows. The starting-point of this overgrowth is the place of obstruction itself, and the degree of the overgrowth depends upon the kind of obstruction. Thus the overgrowth is greatest in animals around whose bile-ducts a ligature has been placed. Here the presence of the ligature, and the accompanying disturbance of all the structures in the porta of the liver, cause a rapid and enormous overgrowth of the connective tissue throughout the whole of the gland. In such cases, I have found, on the fourteenth day after ligaturing the ducts, the most intense cirrhosis, so that the liverstructure seemed made up chiefly of connective tissue, with a fe: dwindled hepatic cells. This overgrowth of the connective tissue begins within a few hours after the operation. (Sce the author's paper on the Changes in the Liver which follow Ligature of the Bile-Ducts, in St. Bartholomew's Hospital Reports, 1873, vol. ix, p. I6r.) On the other hand, if the obstruction be such that the comnective tissue around the bile-duct suffers but little, the increase in the connective tissuc is also but slight. In a case which I have recently examined, in which the obstruction was caused by the pressure of an hydatid cyst upon the hepatic duct, the increase in the connective tissue was small, and did not pass into the lobules. Further, there was an absence of those lymphatic corpuscles, which are so marked a feature in the new connective tissue after ligature of the ducts and in cirrhosis. I attribute this to the uniform elastic pressure of the fluid in the hydatid cyst, so different in its effects from those of a rough angular gall-stone, one of the most common causes of obstruction. In one of these cases, in which it would appear that the obstıuction from the gall-stone was not complete, if the absence of jaundice be taken as evidence on this count, I yet found the connective tissue throughout the liver greatly increased, and containing many new lymphatic elements, so that, at first sight, the section of the liver, seen under the microscope, very strongly recalled a far advanced cirrhosis.

The view that the overgrowth of the connective tissue takes its rise from that surrounding the bile-ducts, is strengthened by the fact that, in all cases of permanent obstruction, the bile-ducts are found greatly thickened. Solowieff (Centralblatt für die Medicinischen Wissenschaften, 1872, No. 22, p. 337) also found the same morbid overgrowth of the 